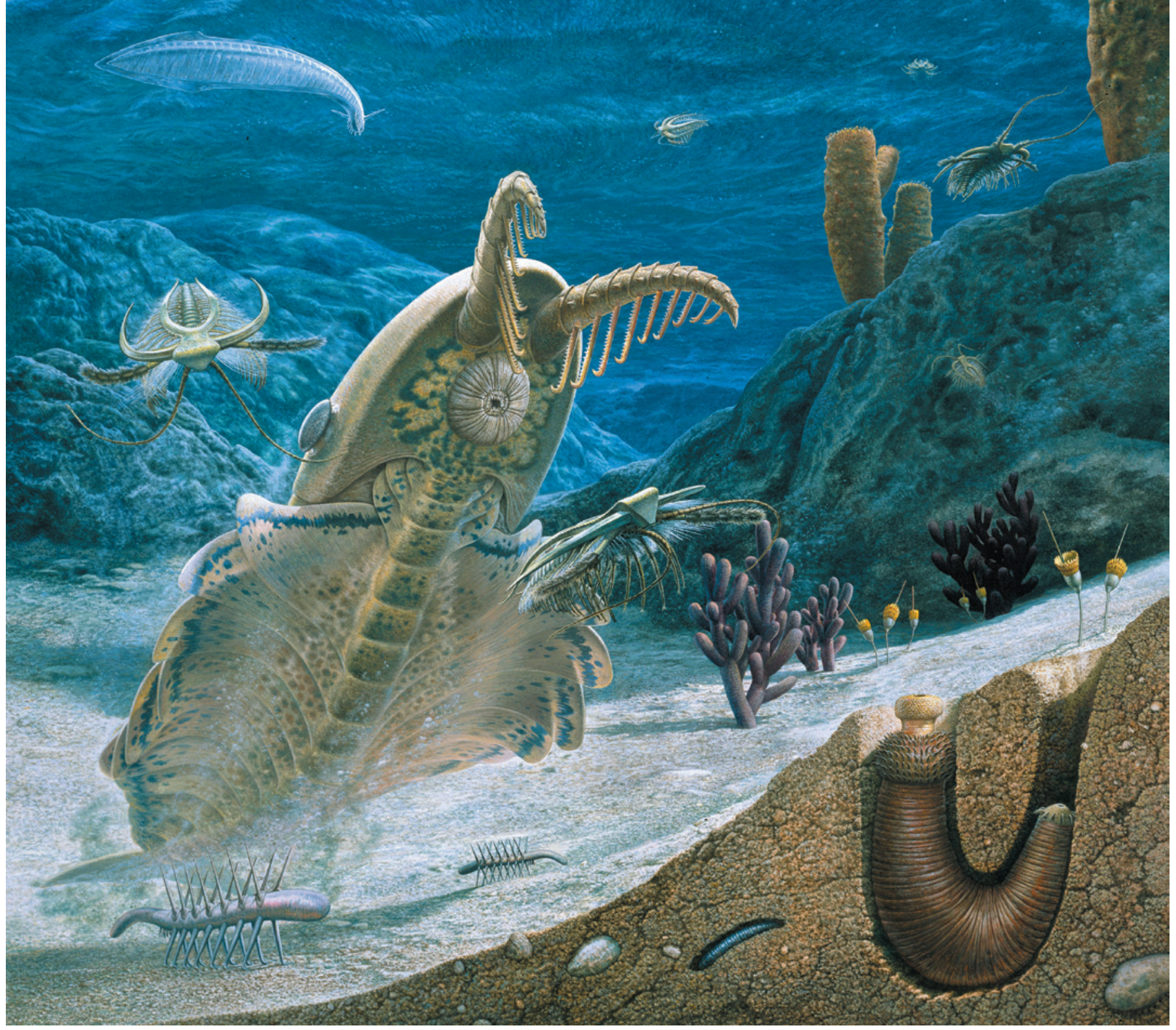

\title{
WHAT SPARKED THE CAMBRIAN EXPLOSION?
}

\author{
An evolutionary burst 540 million years ago filled the seas with an \\ astonishing diversity of animals. The trigger for that revolution is \\ finally coming into focus.
}

\author{
BY DOUGLAS FOX
}

A series of dark, craggy pinnacles rises 80 metres above the grassy plains of Namibia. The peaks call to mind something ancient - the burial mounds of past civilizations or the tips of vast pyramids buried by the ages.

The stone formations are indeed monuments of a faded empire, but not from anything hewn by human hands. They are pinnacle reefs, built by cyanobacteria on the shallow sea floor 543 million years ago, during what is known as the Ediacaran period. The ancient world occupied by these reefs was truly alien. The oceans held so little oxygen that modern fish would have quickly foundered and died there. A gooey mat of microbes covered the sea floor, and on that blanket lived a variety of enigmatic animals whose bodies resembled thin, quilted pillows. Most were stationary, but a few meandered blindly over the slime, grazing on the microbes. Animal life was simple, and there were no predators. But an evolutionary storm would soon upend this quiet world.

Within several million years, this simple ecosystem would disappear, and give way to a world ruled by highly mobile animals that sported modern anatomical features. The Cambrian explosion, as it is called, produced arthropods with legs and compound eyes, worms with feathery gills and swift predators that could crush prey in tooth-rimmed jaws. Biologists have argued for decades over what ignited this evolutionary burst. Some think that a steep rise in oxygen levels sparked the change, whereas others say that it sprang from the development of some key evolutionary innovation, such as vision. The precise cause has remained elusive, in part because so little is known about the physical and chemical environment at that time. 
The Cambrian seas teemed with new types of animal, such as the predator Anomalocaris (centre).

\section{the Ediacaran. Evi-}

dence gathered from the Namibian reefs and other sites suggests that earlier theories were too simplistic - that the Cambrian explosion actually emerged out of a complex interplay between small environmental changes that triggered major evolutionary developments.

Some scientists now think that a small, perhaps temporary, increase in oxygen suddenly crossed an ecological threshold, enabling the emergence of predators. The rise of carnivory would have set off an evolutionary arms race that led to the burst of complex body types and behaviours that fill the oceans today. "This is the most significant event in Earth evolution," says Guy Narbonne, a palaeobiologist at Queen's University in Kingston, Canada. "The advent of pervasive carnivory, made possible by oxygenation, is likely to have been a major trigger."

\section{ENERGY TO BURN}

In the modern world, it's easy to forget that complex animals are relative newcomers to Earth. After life first emerged more than 3 billion years ago, single-celled organisms dominated the planet for most of its history. Thriving in environments that lacked oxygen, they relied on compounds such as carbon dioxide, sulfurcontaining molecules or iron minerals that act as oxidizing agents to break down food. Much of Earth's microbial biosphere still survives on these anaerobic pathways.

Animals, however, depend on oxygen - a much richer way to make a living. The process of metabolizing food in the presence of oxygen releases much more energy than most anaerobic pathways. Animals rely on this potent, controlled combustion to drive such energy-hungry innovations as muscles, nervous systems and the tools of defence and carnivory - mineralized shells, exoskeletons and teeth.

Given the importance of oxygen for animals, researchers suspected that a sudden increase in the amount of the gas in the oceans, to nearmodern levels, could have spurred the Cambrian explosion. To test that idea, they have studied ancient ocean sediments laid down during the Ediacaran and Cambrian periods, which together ran from about 635 million to 485 million years ago.

In Namibia, China and other spots around the world, researchers have collected rocks that were once ancient sea beds, and analysed the amounts of iron, molybdenum and other metals in them. The metals' solubility depends strongly on the amount of oxygen present, so the quantity and type of those metals in ancient sedimentary rocks reflect how much oxygen was in the water, when the sediments formed.

These proxies seemed to indicate that oxygen concentrations in the oceans rose in several steps, approaching today's sea-surface concentrations at the start of the Cambrian, around 541 million years ago - just before more-modern animals suddenly appeared and diversified. This supported the idea of oxygen as a key trigger for the evolutionary explosion.

But last year, a major study ${ }^{1}$ of ancient sea-floor sediments challenged that view. Erik Sperling, a palaeontologist at Stanford University in California, compiled a database of 4,700 iron measurements taken from rocks around the world, spanning the Ediacaran and Cambrian periods. He and his colleagues did not find a statistically significant increase in the proportion of oxic to anoxic water at the boundary between the Ediacaran and the Cambrian.

"Any oxygenation event must have been far, far smaller than what people normally considered," concludes Sperling. Most people assume "that the oxygenation event essentially raised oxygen to essentially modern-day levels. And that probably wasn't the case", he says.

The latest results come at a time when scientists are already reconsidering what was happening to ocean oxygen levels during this crucial period. Donald Canfield, a geobiol-

\section{"This is the most significant event in Earth evolution."}

ogist at the University of Southern Denmark in Odense, doubts that oxygen was a limiting factor for early animals. In a study published last month ${ }^{2}$, he and his colleagues suggest that oxygen levels were already high enough to support simple animals, such as sponges, hundreds of millions of years before they actually appeared. Cambrian animals would have needed more oxygen than early sponges, concedes Canfield. "But you don't need an increase in oxygen across the Ediacaran-Cambrian boundary," he says; oxygen could already have been abundant enough "for a long, long time before".

"The role of oxygen in the origins of animals has been heavily debated," says Timothy Lyons, a geobiologist at the University of California, Riverside. "In fact, it's never been more debated than it is now." Lyons sees a role for oxygen in evolutionary changes, but his own work ${ }^{3}$ with molybdenum and other trace metals suggests that the increases in oxygen just before the Cambrian were mostly temporary peaks that lasted a few million years and gradually stepped up (see 'When life sped up').

\section{MODERN MIRRORS}

Sperling has looked for insight into Ediacaran oceans by studying oxygen-depleted regions in modern seas worldwide. He suggests that biologists have conventionally taken the wrong approach to thinking about how oxygen shaped animal evolution. By pooling previously published data with some of his own and analysing them, he found that tiny worms survive in areas of the sea floor where oxygen levels are very low - less than $0.5 \%$ of average global sea-surface concentrations. Food webs in these oxygenpoor environments are simple, and animals feed directly on microbes. In places where sea-floor oxygen levels are a bit higher - about $0.5-3 \%$ of concentrations at the sea surface - animals are more abundant but their food webs remain limited: the animals still feed on microbes rather than on each other. But around somewhere between $3 \%$ and $10 \%$, predators emerge and start to consume other animals ${ }^{4}$.

The implications of this finding for evolution are profound, Sperling says. The modest oxygen rise that he thinks may have occurred just before the Cambrian would have been enough to trigger a big change. "If oxygen levels were $3 \%$ and they rose past that $10 \%$ threshold, that would have had a huge influence on early animal evolution," he says. "There's just so much in animal ecology, lifestyle and body size that seems to change so dramatically through those levels."

The gradual emergence of predators, driven by a small rise in oxygen, would have meant trouble for Ediacaran animals that lacked obvious defences. "You're looking at soft-bodied, mostly immobile forms that probably lived their lives by absorbing nutrients through their skin," says Narbonne.

Studies of the ancient Namibian reefs suggest that animals were indeed starting to fall prey to predators by the end of the Ediacaran. When palaeobiologist Rachel Wood from the University of Edinburgh, UK, examined the rock formations, she found spots where a primitive animal called Cloudina had taken over parts of the microbial reef. Rather than spreading out over the ocean floor, these cone-shaped creatures lived in crowded colonies, which hid their vulnerable body parts from predators - an ecological dynamic that occurs in modern reefs ${ }^{5}$.

Cloudina were among the earliest animals known to have grown hard, mineralized exoskeletons. But they were not alone. Two other types of animal in those reefs also had mineralized parts, which suggests that multiple, unrelated groups evolved skeletal shells around the same time. "Skeletons are quite costly to produce," says Wood. "It's very difficult to come up with a reason other than defence for why an animal should bother to create a skeleton for itself.' Wood thinks that the skeletons provided protection against newly evolved predators. Some Cloudina fossils from that period even have holes in their sides, which scientists interpret as the marks of attackers that bored into the creatures' shells ${ }^{6}$.

Palaeontologists have found other hints that animals had begun to eat each other by the late Ediacaran. In Namibia, Australia and Newfoundland in Canada, some sea-floor sediments have preserved an unusual type of tunnel made by an unknown, wormlike creature ${ }^{7}$. Called Treptichnus burrows, these warrens branch again and again, as if a predator just below the 


\section{When life sped up}

Big animals emerged during the Ediacaran period, but these creatures were slow or immobile. A rise in oceanic oxygen concentrations at the end of the period might have helped to trigger the Cambrian evolutionary explosion.

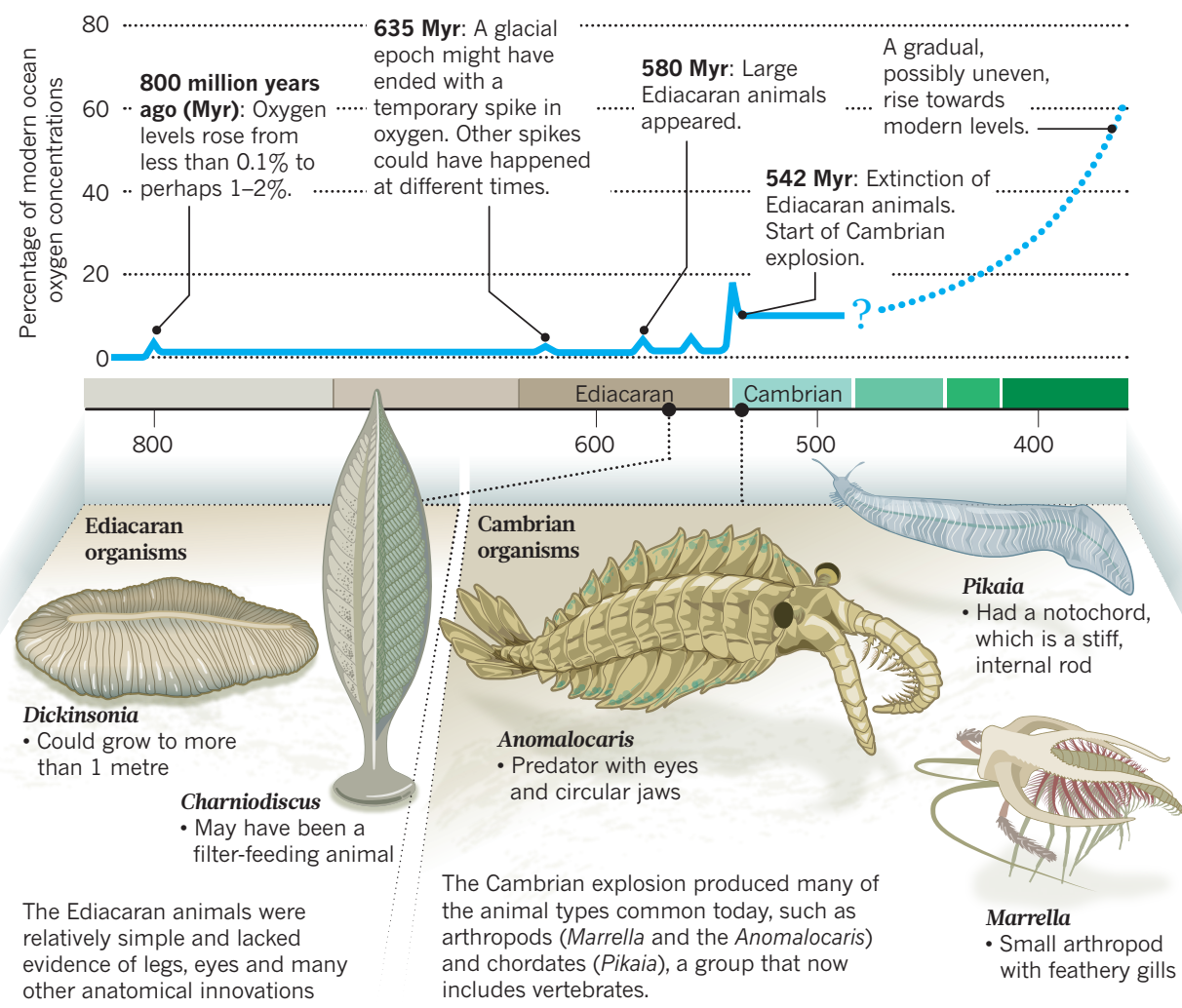

microbial mat had systematically probed for prey animals on top. The Treptichnus burrows resemble those of modern priapulid, or 'penis', worms - voracious predators that hunt in a remarkably similar way on modern sea floors 8

The rise of predation at this time put large, sedentary Ediacaran animals at a big disadvantage. "Sitting around doing nothing becomes a liability," says Narbonne.

\section{THE WORLD IN 3D}

The moment of transition from the Ediacaran to the Cambrian world is recorded in a series of stone outcrops rounded by ancient glaciers on the south edge of Newfoundland. Below that boundary are impressions left by quilted Ediacaran animals, the last such fossils recorded on Earth. And just 1.2 metres above them, the grey siltstone holds trails of scratch marks, thought to have been made by animals with exoskeletons, walking on jointed legs - the earliest evidence of arthropods in Earth's history.

No one knows how much time passed in that intervening rock - maybe as little as a few centuries or millennia, says Narbonne. But during that short span, the soft-bodied, stationary Ediacaran fauna suddenly disappeared, driven to extinction by predators, he suggests.

Narbonne has closely studied the few fauna that survived this transition, and his findings suggest that some of them had acquired new, more complex types of behaviour. The best clues come from traces left by peaceful, wormlike animals that grazed on the microbial mat. Early trails from about 555 million years ago meander and criss-cross haphazardly, indicating a poorly developed nervous system that was unable to sense or react to other grazers nearby - let alone predators. But at the end of the Ediacaran and into the early Cambrian, the trails become more sophisticated: creatures carved tighter turns and ploughed closely spaced, parallel lines through the sediments. In some cases, a curvy feeding trail abruptly transitions into a straight line, which Narbonne interprets as potential evidence of the grazer evading a predator?.

This change in grazing style may have contributed to the fragmentation of the microbial mat, which began early in the Cambrian. And the transformation of the sea floor, says Narbonne, "may have been the most profound change in the history of life on Earth"10,11. The mat had previously covered the sea bed like a coating of plastic wrap, leaving the underlying sediments largely anoxic and off limits to animals. Because animals could not burrow deeply in the Ediacaran, he says, "the mat meant that life was two-dimensional". When grazing capabilities improved, animals penetrated the mat and made the sediments habitable for the first time, which opened up a 3D world.

Tracks from the early Cambrian show that animals started to burrow several centimetres into the sediments beneath the mat, which provided access to previously untapped nutrients - as well as a refuge from predators. It's also possible that animals went in the opposite direction. Sperling says that the need to avoid predators (and pursue prey) may have driven animals into the water column above the sea bed, where enhanced oxygen levels enabled them to expend energy through swimming.

The emerging evidence about oxygen thresholds and ecology could also shed light on another major evolutionary question: when did animals originate? The first undisputed fossils of animals appear only 580 million years ago, but genetic evidence indicates that basic animal groups originated as far back as 700 million or 800 million years ago. According to Lyons, the solution may be that oxygen levels rose to perhaps $2 \%$ or $3 \%$ of modern levels around 800 million years ago. These concentrations could have sustained small, simple animals, just as they do today in the ocean's oxygen-poor zones. But animals with large bodies could not have evolved until oxygen levels climbed higher, in the Ediacaran.

Understanding how oxygen influenced the appearance of complex animals will require scientists to tease subtler clues out of the rocks. "We've been challenging people working on fossils to tie their fossils more closely to our oxygen proxies," says Lyons. It will mean deciphering what oxygen levels were in different ancient environments, and connecting those values with the kinds of traits exhibited by the animal fossils found in the same locations.

Late last year, Woods visited Siberia with that goal in mind. She collected fossils of Cloudina and another skeletonized animal, Suvorovella, from the waning days of the Ediacaran. The sites gave her the chance to gather fossils from many different depths in the ancient ocean, from the more oxygen-rich surface waters to deeper zones. Wood plans to look for patterns in where animals grew tougher skeletons, whether they were under attack by predators and whether any of this had a clear link with oxygen levels. "Only then can you pick out the story."

Douglas Fox is a journalist in northern California.

1. Sperling, E. A. et al. Nature 523, 451-454 (2015)

2. Zhang, S. et al. Proc. Natl Acad. Sci. USA http:// dx.doi.org/10.1073/pnas.1523449113 (2016).

3. Sahoo, S. K. et al. Geobiology (in the press).

4. Sperling, E. A. et al. Proc. Natl Acad. Sci. USA 110 13446-13451 (2013)

5. Wood, R. A. et al. Precambrian Res. 261, 252-271 (2015).

6. Bengtson, S. \& Zhao, Y. Science 257, 367-369 (1992).

7. Seilacher, A., Buatois, L. A. \& Mángano, M. G. Palaeogeog. Palaeoclimatol. Palaeoecol. 227, 323-356 (2005).

8. Vannier, J., Calandra, I., Gaillard, C. \& Zylinska, A. Geology 38, 711-714 (2010).

9. Carbone, C. \& Narbonne, G. M. J. Paleontol. 88, 309-330 (2014).

10.Mángano, M. G. \& Buatois, L. A. Proc. R. Soc. B 281, 20140038 (2014).

11.Buatois, L. A., Narbonne, G. M., Mángano, M. C., Carmona, N. B. \& Myrow, P. Nature Commun. 5, 3544 (2014). 